\title{
Presentación. Cuerpos, sexualidades y poder
}

Bodies, sexualities and power

José María Valcuende del Río

Universidad Pablo de Olavide (Sevilla). Investigador invitado de la Universidad de Cuenca (Ecuador). Proyecto Prometeo

(SENECYT).

jmvalrio@upo.es

\author{
CUERPOS, SEXUALIDADES Y PODER \\ MONOGRÁFICO COORDINADO POR JOSÉ MARÍA VALCUENDE. Universidad Pablo de Olavide (Sevilla).
}

RESUMEN

Los artículos que componen este número monográfico nos aproximan a dos ámbitos profundamente relacionados: los cuerpos y las sexualidades. Para ello, se analizan aspectos como las identidades corporales y sexuales, los modelos sociales en torno al cuerpo y la sexualidad, la significación de las prácticas sexuales, los sistemas de creencias en torno al cuerpo o las relaciones de poder que se plasman en la visualización o negación de determinados cuerpos y prácticas sexuales.

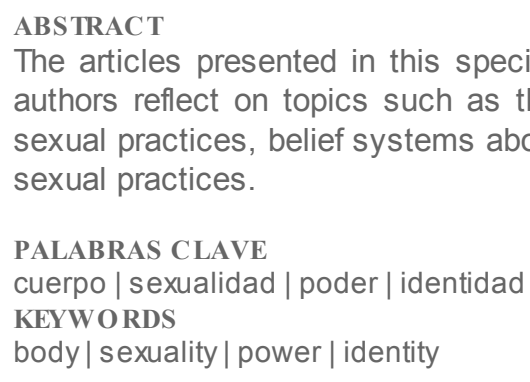
sexual practices.

PALABRAS CLAVE

cuerpo | sexualidad | poder | identidad

KEYWORDS

body | sexuality | power | identity

The articles presented in this special issue bring us to two subjects deeply interrelated: bodies and sexualities. To do so the authors reflect on topics such as the body and sexual identities, social patterns concerning body and sexuality, meanings of sexual practices, belief systems about the body, or the power relationships reflected in the display, or denial, of some bodies and

Las investigaciones sobre la sexualidad, o si se prefiere las sexualidades, van encontrando progresivamente un campo propio de indudable interés, en cuanto que nos permiten pensarnos desde las vivencias de unos cuerpos marcados por el dolor, el placer, al amor, el juego, el deseo y, cómo no, el poder. Precisamente, los textos seleccionados en este monográfico evidencian una pluralidad de miradas disciplinares y metodológicas que enriquecen a una ciencia como la Antropología Social, caracterizada por ser, si se me permite el símil, especialmente "promiscua". No es extraño, por tanto, que encontremos perspectivas antropológicas, sociológicas, psicológicas y del trabajo social, como no podría ser de otro modo en una temática tan poliédrica. Como tampoco lo es que los casos analizados provengan de España y América Latina, ya que este monográfico se realiza en colaboración con la joven, pero pujante, Red LIESS (Laboratorio Iberoamericano para el Estudio Sociohistórico de las Sexualidades), reconocida oficialmente por la AUIP, que se empieza a conformar hace tres años bajo los auspicios del Proyecto I+D+i financiado por el Ministerio de Economía y Competitividad (FEM2011-27295), y en la que se articulan investigadores de diferentes universidades de Argentina, Brasil, Cuba, Colombia, Costa Rica, Chile, Ecuador, Estados Unidos, México, Perú, Uruguay, Portugal.

Los trabajos presentados muestran una realidad compleja y mal interpretada habitualmente como puramente "biológica", en cuanto que la sexualidad, pese a su carácter autónomo como ámbito de investigación, está profundamente vinculada con la construcción cultural del cuerpo y el género, pero también con el contexto social e histórico, a partir del que se definen las "buenas" y "malas" prácticas, e incluso qué es y qué no es sexualidad. Este carácter contextual e histórico hace especialmente difícil su investigación, sobre todo porque estamos hablando de una realidad que, por un lado, encierra múltiples significaciones y que, por otro, tiende a ser protegida de la mirada del investigador. Por todo esto, el estudio de las sexualidades presenta numerosos problemas, uno de ellos es el carácter sexuado y sexual de los propios investigadores, que viven con otras personas con las que mantienen relaciones de diverso tipo, 
también de carácter afectivo y/o sexual. El artículo de Carmen Gregorio y Ana Alcázar, "Trabajo de campo en contextos racializados y sexualizados: cuando la decolonialidad se inscribe en nuestros cuerpos", nos aproxima a un tema apasionante, que tiene que ver precisamente con la centralidad del cuerpo en los contextos de investigación, en función del sexo, la raza y la posición socioeconómica. Un texto valiente y honesto que hace algo que no es muy habitual, reflexionar sobre la significación de los cuerpos en ámbitos como la investigación, marcados, como no podía ser de otra forma, por relaciones de poder. Una mirada transformadora en tanto que desacraliza la falsa imagen aséptica de la investigación y pone sobre la mesa una cuestión crucial, que debe permitirnos repensarnos en cuanto cuerpos que observan y que al mismo tiempo son observados.

Y es que analizar la sexualidad no es fácil, sobre todo si queremos salirnos de los caminos "trillados", tal y como hace José Antonio Langarita en "Rituales de interacción sexual entre hombres. Una propuesta de análisis del discurso y de la práctica del sexo anónimo". El autor va más allá de los discursos para adentrarnos en un mundo de prácticas, que se sustancian en la invisibilidad, y que ponen de manifiesto una forma de entender la sexualidad descargada de muchas de las convenciones sociales (no es monógama, se hace en un espacio público, no implica más compromiso que el propio encuentro puntual...), aunque al mismo tiempo reproduce, como no podía ser de otra forma, las relaciones de poder, en buena medida definidas por la significación social de los cuerpos (la centralidad del pene) muy vinculada a la idea dominante de masculinidad.

Si en el texto de Langarita la masculinidad y sexualidad juegan un papel importante, en el caso de los textos de Laia Folguera y Jordi Caïs, por un lado, y Alejandra Salguero y María Marco, por otro, son la masculinidad y la paternidad las que serán analizadas desde situaciones bien diversas, lo que pone de manifiesto el resurgimiento de las investigaciones sobre las vivencias de los cuerpos de los hombres.

El artículo de Alejandra Salguero y María Marco, "Reflexiones sobre sexualidad y reproducción en estudiantes universitarios en México", nos aproxima a las nociones de los estudiantes universitarios mexicanos en torno a la sexualidad y la reproducción. Para ello realizan una investigación de carácter cualitativo, lo que permite abordar esta realidad social desde las experiencias y vivencias de los estudiantes, a partir del análisis de sus discursos que se centran, de una forma significativa, en las vivencias de la paternidad. En este texto son los hombres y la paternidad los que son "objeto" de análisis, desde una mirada micro que nos permite ganar en profundidad, aunque perdamos perspectiva en superficie.

Laia Folguera y Jordi Caïs, en "Estrategias de gestión de la paternidad dañada en varones víctima de violencia de pareja", nos muestran un hecho social considerado socialmente como anecdótico o excepcional, a pesar de que sus dimensiones son difíciles de determinar, dado que las víctimas de violencia en el seno de la pareja son hombres, heterosexuales y en algunos casos de buena posición económica, es decir, aquellos cuyos cuerpos representan la imagen del poder. Una imagen difícilmente compatible en el imaginario social con su papel de víctimas. El caso propuesto por estos autores es pionero en el caso español y adquiere un especial interés en cuanto que visibiliza la realidad, hasta hora invisible, de unos hombres para los que es especialmente difícil asumir su posición de víctimas, al igual que también lo es para las propias instituciones, que deben abordar este tipo de situaciones.

Pero si el texto anterior se centra en unos hombres que, más allá de los discursos, no se adecuan al modelo dominante de masculinidad, Mario Jordi, en "El músculo negado. Placer artesano y relaciones socioafectivas en el culturismo femenino", nos aproxima a unas mujeres que tampoco se ajustarían a la idea dominante de feminidad. Para ello, analiza la construcción de los cuerpos de las culturistas, partiendo de las entrevistas y de una herramienta de una especial potencia en este tipo de investigaciones, pese a las dificultades que plantea: la observación directa, en este caso, en los gimnasios.

La significación de los cuerpos está indisolublemente vinculada con una identidad internalizada y también impuesta, como también evidencian los dos artículos a los que nos aproximaremos a continuación. Oscar Guasch y Jordi Mas, en "La construcción médico-social de la transexualidad en España (1970-2014)", analizan en clave sociohistórica la evolución que han experimentado los cuerpos que socialmente son reconocidos como "fronterizos". Para ello, abordan los diferentes sentidos y significaciones que, desde la transición española, han adquirido términos como travesti, travesti operado y transexual, reconociendo el importante papel que tanto travestis como transexuales han jugado en la liberación sexual de los disidentes sexuales, pero también en el cuestionamiento de un rígido sistema sexo-genérico. 
Si Guasch y Mas toman como referente el caso español, Rafael Cáceres y José María Valcuende, en "Globalización y diversidad sexual: gays y mariquitas en Andalucía", se centran en el sur de España para aproximarnos a la centralidad de la figura del mariquita, poniendo en evidencia los procesos de hibridación que se han producido entre el modelo que, sin entrar en debates terminológicos, podríamos definir como "tradicional" y el nuevo modelo gay. Un trabajo que evidencia, primero, lo paradójico del reconocimiento social de estos hombres, en base precisamente a la ocultación de cualquier manifestación pública de una sexualidad que implicaba feminización y, por tanto, estigmatización; segundo, las transformaciones experimentadas a partir de la asunción de nuevos modelos en un progresivo proceso de visibilizar otros cuerpos y otras sexualidades.

Es precisamente la marca del estigma la que se pone de manifiesto en los dos trabajos a los que nos referiremos ahora, los cuales abordan, partiendo de perspectivas diferentes, aspectos relacionados con lo que podríamos definir como mercado del sexo, desde la atención sanitaria a las trabajadoras sexuales en Latinoamérica y el Caribe al oscuro negocio de la trata de personas convertidas en mercancía sexual. Mario Pecheny, en "Estigma y discriminación en los servicios de salud a las mujeres trabajadoras sexuales en América Latina y el Caribe", se centra en la atención sanitaria a las trabajadoras sexuales en quince países, desde una metodología de investigación cuantitativa y cualitativa, lo que permite articular un enfoque macro con una perspectiva que no olvida dar voz a las trabajadoras sexuales. Nuria Cordero, por último, en "Trata con fines de explotación sexual. Humanos que mal-tratan a las humanas", analiza cómo se aborda la trata de mujeres en las propuestas normativas vigentes, haciendo especial hincapié en las aportaciones proporcionadas por el enfoque crítico de los derechos humanos. Una perspectiva que incide en "los dispositivos estructurales", tanto económicos como sociales que facilitan, cuando no legitiman, un pujante negocio que está en la base de esa forma de esclavitud contemporánea. 